\section{Brick by brick}

\section{A small non-profit organization shows how to reduce the vulnerability of poor countries to earthquakes, says Daniel Sarewitz.}

C riven by population growth, urbanization and poverty, earthquake casualties worldwide continue to rise. The latest event struck on 14 April in western China, killing more than 2,200 people - a grisly coda to January's catastrophe in Haiti, which left about 230,000 dead.

These disasters are no surprise, and they teach us little that is new. After each one, offers of help come from many quarters. Scientists want to do their part, which often means promising new information that will help to make things better in the future. For example, the Global Earthquake Model (GEM), a public-private partnership initiated by the Organisation for Economic Co-operation and Development and funded in significant part by insurance companies, says it will focus on "underserved areas such as Haiti ... [to] make sure that organizations, (local) governments and individuals have access to its state-of-the-art risk assessment software and tools as a necessary first step towards taking mitigation action".

Yet "access" to information delivered via the latest technological interfaces is not what developing countries such as Haiti need to better protect themselves against earthquakes. Much more important are institutional and social arrangements that can mobilize existing knowledge and resources. Such arrangements do not emerge spontaneously in countries that are struggling to meet the basic needs of citizens. A catalyst is required.

\section{You don't have to be rich}

In 1991, seismologist Brian Tucker left his job as deputy chief at the California Division of Mines and Geology and founded GeoHazards International (GHI) in Palo Alto, California, to help reduce earthquake vulnerability in developing countries. The non-profit organization's approach is improvisational and personal. "When we go to a new setting, we try to find out who is really interested in doing something to improve earthquake safety," Tucker says. "We have to find people who are really passionate and will carry on once we're gone. We try to build up the credibility of these people, and get more resources to do what they want. We work with who we find, in their profession, not try to change them into something they're not."

In the mid-1990s when GHI wanted to start

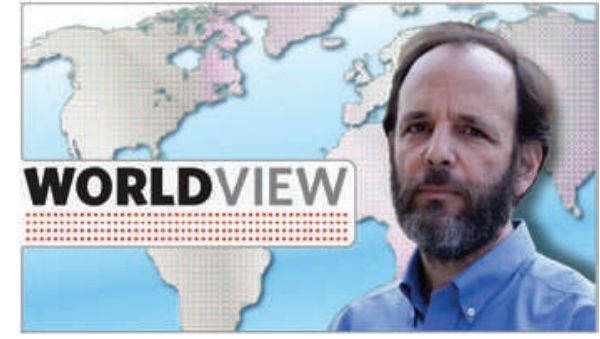

a project in Nepal's Kathmandu Valley, Tucker met Amod Dixit, a geotechnical engineer who hoped to start a local non-profit organization to reduce the risk from earthquakes in his country. GHI worked with Dixit to support demonstration projects around Kathmandu that could build visibility and a sense of possibility. In one such project, local engineers trained masons to strengthen a school. Walls were connected together with steel mesh, and joined to the roof and floor with iron bars. The building's single exit door was rehung so that it opened outwards, and a second exit was added. "People who lived nearby watched as the work progressed," says Tucker. "The magic thing is that when I came back ten years later, Ilearned that when people in this village wanted to add onto their house or build a new house, they would get advice from the masons from our project on how to do it correctly. And the masons trained other masons in the area, while Dixit's non-profit exported the approach to many other villages in the region."

In contrast to the Nepal project, GHI's work in Delhi, India, found its passionate collaborators in the city's public-works department,
"Knowledge that is useful is knowledge that emerges within a particular social and institutional context." to show what they could do." By the project's end, two buildings were retrofitted, five other schools were identified for future repair and the public-works department had the capacity to continue this work after GHI was gone.

GHI's newest project is in Padang, Indonesia, a city of about 1 million inhabitants that occupies a flat plain at sea level. Last September 1,000 people died there in an earthquake. But given Padang's location, the much greater danger is tsunamis. The latest research on wave height and return period doesn't address Padang's needs; the real problem is simply that there is not enough time to evacuate. Immediately after September's earthquake many residents, fearing a tsunami, sought higher ground but instead ended up in a massive traffic jam. No tsunami occurred, but the likelihood of one in the future is high, and the death toll could reach 100,000.

\section{How to save 100,000 lives}

Unlike other cities where thousands of buildings would need to be retrofitted to save 100,000 lives, in Padang it would only take a half-dozen or so elevated parks in the city to allow for 'vertical evacuation'. Constructing these facilities would not only be relatively cheap and simple, but would yield immediate psychological benefits by assuaging the sense of foreboding and powerlessness that Padang's residents live with every day. GHI is now seeking funds to start this work.

What makes GHI distinct from big-science, high-tech endeavours such as GEM is that Tucker starts by understanding and immersing himself in the local context of the problem that needs to be solved. GEM starts in the opposite place, offering the latest science and tools to solve a problem regardless of whether that's what the problem demands. This approach reflects a great fallacy of the modern ideology of science: that scientific knowledge is where officials were concerned about the vulnerability of crucial public buildings. India has many highly qualified seismologists and earthquake engineers at its excellent technical universities, but they weren't well connected to one other or to government workers responsible for protecting the city against earthquakes. So GHI acted as a neutral organizer, using international earthquake experts to get the attention of the nation's top academics, and bringing them together with city officials to design ways to strengthen existing hospitals, schools and police stations. "Believe it or not," says Tucker, "our project was the first chance for many of these people to come together a public good, equally available and potentially equally beneficial to all. But knowledge that is useful - and used - is knowledge that emerges within a particular social and institutional context. If scientists are serious about helping to reduce the vulnerability of poor regions to earthquakes and other hazards, they would do well to emulate the model of GeoHazards International.

Daniel Sarewitz, co-director of the Consortium for Science, Policy and Outcomes at Arizona State University, is based in Washington DC. e-mail: dsarewitz@gmail.com.

See go.nature.com/ILx8PC for more columns. 